\title{
Regionalização da agricultura do Estado do Paraná, Brasil.
}

\author{
Agriculture regionalization of Paraná State, Brazil. \\ Rafael Fuentes Llanillo ${ }^{1}$ Mauro Eduardo Del Grossi ${ }^{2}$ \\ Flávio Oliveira dos Santos ${ }^{2}$ Paula Daniela Munhos² \\ Maria de Fátima Guimarães ${ }^{3}$
}

\section{RESUMO}

Este trabalho apresenta uma caracterização da agricultura do estado do Paraná com base em trinta e cinco variáveis extraídas do Censo Agropecuário de 1995/96 e duas variáveis extraídas do Mapa de Aptidão Agrícola das Terras. As mesmas dizem respeito ao acesso à terra, uso da terra, uso de tecnologias químicas e mecânicas, uso de capital, relações de trabalho, terceirização, fertilidade natural dos solos e possibilidade de mecanização. A Análise Fatorial com trinta e sete variáveis permitiu descrever os sete fatores principais que explicaram 66,7\% da variância. A Análise de Agrupamento dos valores dos sete fatores permitiu classificar dez tipos de municípios, organizados em nove mesorregiões.

Palavras-chave: regionalização agrícola, tipologia de municípios, análise fatorial, análise de agrupamento, análise cluster.

\section{ABSTRACT}

This work presents a characterization of the agriculture of Paraná State based on thirty-five variables extracted from Agricultural Census of 1995/96 and two variables from the Map of Soil Aptitude. These are related to land access, land use, utilization of chemical and mechanical technologies, use of capital assets, labor relationships and tercerization, soil fertility and mechanization suitability. The Factor analysis with thirty-seven variables enabled to describe seven main factors, which explained $66.7 \%$ of variance. The Cluster analysis of the seven factor's values allowed to classify ten types of municipalities organized in nine regions.

Key words: agriculture regionalization, typology of municipalities, factor analysis, cluster analysis.

\section{INTRODUÇÃO}

A aplicação de políticas públicas na agricultura como a pesquisa e a extensão rural, assim como as iniciativas dos agentes da iniciativa privada e das organizações não governamentais devem estar calcadas nas características de cada região e dos municípios que a integram. Conforme foi destacado por CAMPANHOLA \& GRAZIANODA SILVA(2000), qualquer iniciativa de planejamento local deve se iniciar pela regionalização socioeconômica e ambiental dos recursos disponíveis e pelo zoneamento territorial de modo que se tenha uma ocupação organizada tanto local como regional, respeitando os princípios do desenvolvimento sustentável. Na mesma direção, SCHNEIDER \& WAQUIL (2001) apontam que um diagnóstico analítico e descritivo das regiões, das características dos municípios e das populações revelase uma etapa fundamental para apontar conhecimentos que possam ser úteis ao planejamento e avaliação de ações que visem minimizar ou erradicar as situações de pobreza rural e as desigualdades regionais que ocorrem tanto em áreas de predomínio das pequenas propriedades quanto daquelas de maior tamanho.

No intuito de realizar regionalizações a partir de um grande número de variáveis, diversos trabalhos no Brasil têm- se utilizado de métodos estatísticos de

${ }^{1}$ Instituto Agronômico do Paraná (IAPAR) Caixa Postal 481, 86001-970 Londrina, PR, Brasil. E - mail: rfuentes@iapar.br. Autor para correspondência.

${ }^{2}$ IAPAR, Londrina, PR, Brasil.

${ }^{3}$ Departamento de Agronomia da Universidade Estadual de Londrina (UEL), Londrina, PR, Brasil. 
Análise Fatorial e Análise de Agrupamento. Para caracterizar a estrutura da produção agropecuária do Paraná, FUENTES LLANILLO (1984) utilizou a Análise Fatorial com trinta variáveis, segundo as microrregiões homogêneas do estado, a partir dos dados do Censo Agropecuário do IBGE de 1980 e do Mapa de Aptidão Agrícola das Terras, chegando a oito zonas diferenciais de estrutura agrária. Para estudar a dinâmica da modernização da agricultura em cento e cinqüenta e sete microrregiões homogêneas de oito estados brasileiros, HOFFMANN (1992) utilizou com sucesso a Análise Fatorial a partir de informações dos Censos Agropecuários do IBGE de 1975 e 1980 (IBGE, 1979 e 1983). A título de atualização e aperfeiçoamento metodológico FUENTES LLANILLO et al. (1993) realizaram uma nova regionalização do estado do Paraná, desta vez com o uso sequiencial de Análise Fatorial e Análise de Agrupamento, e tendo os municípios como unidades de análise, a partir de trinta e três variáveis do Censo Agropecuário de 1985 (IBGE, 1991) e mais duas variáveis de solos, de onde foram identificadas oito mesorregiões. Ao estudar a terceirização na produção agrícola do Paraná, LAURENTI (2000) fez uma releitura da regionalização feita por FUENTES LLANILLO et al.(1993), e incorporou com sucesso uma variável de uso de força de tração de propriedade de terceiros nos trabalhos agrários, o que suscitou a inclusão de três variáveis relativas à terceirização no presente trabalho. Incorporando uma visão demográfica ao assunto, KAGEYAMA \& LEONE (1999) realizaram um trabalho de tipologia dos municípios do estado de São Paulo com indicadores extraídos dos Censos Demográficos de 1980 e 1991, com especial interesse sobre o emprego e ocupações na agricultura e, mais particularmente, das combinações de ocupações (pluriatividade). Mais recentemente CUNHA \& CHILANTE (2001), com base nos dados do Censo Agropecuário de 1995/96 (IBGE, 1998) fizeram uma caracterização da agropecuária do Paraná identificando oito regiões homogêneas, também utilizando métodos de Análise Fatorial e de Agrupamento, sem abordar aspectos da qualidade dos solos. Para o Rio Grande do Sul, SCHNEIDER \& WAQUIL (2001), utilizando dados do Censo Agropecuário de 1995/96 do IBGE (IBGE, 1998), obtiveram uma caracterização socioeconômica dos municípios gaúchos identificando as desigualdades regionais.

O objetivo deste artigo é caracterizar grupos ou tipos homogêneos de municípios do Paraná, a partir de um elenco de indicadores mensuráveis relativos a fatores econômicos, sociais, tecnológicos e dos recursos naturais na agricultura.

\section{MATERIAL E MÉTODOS}

Foram selecionadas trinta e cinco variáveis extraídas do Censo Agropecuário do Paraná 1995/96 (IBGE, 1998) e duas variáveis extraídas do mapa de Aptidão Agrícola das Terras do Paraná (MINISTERIO DAAGRICULTURA, 1981). Na listagem a seguir, são apresentadas as trinta e sete variáveis que abrangem acesso à terra, uso da terra, uso de tecnologias químicas e mecânicas, uso de capital, relações de trabalho, terceirização e solos, tendo sido calculadas para cada um dos 371 municípios existentes em 1995/96.

01 - Índice de Gini

02 - Área média dos estabelecimentos

03 - Porcentagem da área dos 50\% menores estabelecimentos (A 50-).

04 - Porcentagem da área dos 5\% maiores estabelecimentos (A 5+).

05 - Porcentagem da área de lavouras permanentes na área total ocupada.

06 - Porcentagem da área de lavouras temporárias na área total ocupada.

07 - Porcentagem da área de lavouras em descanso (pousio) na área total ocupada.

08 - Porcentagem da área de pastagens plantadas na área total ocupada.

09 - Porcentagem da área de matas e florestas naturais na área total ocupada.

10 - Porcentagem da área de terras produtivas não utilizadas na área total ocupada.

11 - Porcentagem dos estabelecimentos com trator.

12- Porcentagem dos estabelecimentos com colhedoras.

13 - Área explorada por trator (ha).

14 - Porcentagem de mão-de-obra familiar no total de equivalentes-homem.

15 - Porcentagem de empregados permanentes no total de equivalentes-homem.

16 - Porcentagem de empregados temporários no total de equivalentes-homem.

17 - Porcentagem de parceiros e de outra condição no total de equivalentes-homem.

18 - Porcentagem dos estabelecimentos que utiliza adubos.

19- Porcentagem dos estabelecimentos que utiliza calcário.

20 - Porcentagem dos estabelecimentos com controle de parasitas e doenças animais.

21 - Porcentagem dos estabelecimentos com controle de pragas e doenças vegetais. 
22- Valor dos financiamentos por área explorada ( $\mathrm{R} \$ / \mathrm{ha})$.

23 - Valor dos investimentos por área explorada (R $\$ / h a)$.

24- Receitas menos despesas por área explorada ( $\mathrm{R} \$ / \mathrm{ha})$.

25 - Participação percentual das áreas de milho e de feijão na área total ocupada.

26 - Participação percentual da área de soja na área total ocupada.

27 - Participação percentual da área de algodão na área total ocupada.

28 - Participação percentual da área de café na área total ocupada.

29 - Porcentagem dos estabelecimentos com serviços de empreitada no preparo do solo.

30 - Unidades animais de bovinos e bubalinos por ha de área explorada.

31 - Unidades animais de suínos por ha de área explorada.

32 - Unidades animais aves por ha de área explorada.

33 - Participação percentual da área de trigo na área total ocupada.

34 - Percentual área nível baixo/médio de exigência de fertilizantes (\% solos férteis)

35 - Percentual área nível alto/médio de possibilidade de mecanização (\% solos mecanizáveis)

36 - Porcentagem de uso de força de tração de terceiros (aluguel de máquinas).

37 - Porcentagem dos estabelecimentos com serviços de empreitada (total).

Foram utilizados dois métodos estatísticos de Análise Multivariada em sequiência: Análise Fatorial pelo método dos Componentes Principais e Análise de Agrupamento pelo método da Média Aritmética. Para processamento dos dados utilizou-se o software Statistical Program for Social Sciences (SPSS), versão 7.5 for Windows, adotando $5 \%$ de probabilidade de erro.

A Análise Fatorial é uma técnica que permite representar a interdependência entre as variáveis coletadas, de tal forma a se obter um número menor de variáveis denominadas fatores. Essa técnica tem por objetivo fundamental explicar a variação de um conjunto de variáveis a partir de variados fatores ortogonais ou independentes entre si (HOFFMANN, 1992). Há diversos métodos para realizar uma Análise Fatorial, tendo-se eleito o dos Componentes Principais (HARMAN, 1976). Em função de críticas sofridas sobre o modelo utilizado em 1993 de que a rotação Varimax estaria artificializando a interpretação dos fatores, optou-se ainda por não fazer rotação dos fatores, fato que não afetou a essência da análise. Os principais produtos da análise são a matriz de estrutura dos fatores (factor loadings ou cargas fatoriais) e os valores dos fatores de cada município (factor scores).
A Análise de Agrupamento é um dos tipos de Análise Multivariada cujo objetivo é o agrupamento das observações de acordo com as suas semelhanças (MORRISON, 1976; JOHNSON \& WICHERN, 1982). Elegeu-se fazer a Análise de Agrupamento pelo método da Média Aritmética (K-means no SPSS) e as observações foram os valores dos sete fatores para cada município. O principal produto da análise é a constituição dos grupos ou tipos de municípios.

\section{RESULTADOS E DISCUSSÃO}

Como resultados da Análise Fatorial, apresentam-se na tabela 1 as estruturas dos sete fatores principais, a variância explicada total e por fator, além das comunalidades das variáveis. Nesse particular, dezoito variáveis apresentam altas comunalidades, catorze apresentam médias comunalidades e cinco apresentam baixas comunalidades. Essas últimas têm baixo poder de explicação, e quatro delas não têm correlação forte com nenhum fator. A variância explicada pelo modelo foi de $66,7 \%$, e a seguir é descrita a estrutura de cada um dos sete fatores e sua denominação.

\section{Fator 1 - Agricultura Moderna de Grãos}

Agricultura Moderna de Grãos é o principal fator da análise e explica 21,6\% da variância. Apresenta correlações acima de 0,5 ou abaixo de $-0,5$ com catorze variáveis. Está correlacionado positivamente com a porcentagem da área dos 50\% menores estabelecimentos (A50-), com a porcentagem da área de lavouras temporárias, de soja, de trigo, de milho mais feijão, com a porcentagem de estabelecimentos que têm tratores, que têm colhedoras, que utilizam adubos, que utilizam controle de pragas e doenças vegetais e com a porcentagem de terras de alta fertilidade. Correlaciona-se negativamente com o Índice de Gini, com a porcentagem da área dos $5 \%$ maiores estabelecimentos (A5+), com a porcentagem da área de pastagens plantadas e com área por trator. Em resumo, esse fator traduz menor desigualdade no acesso à terra, maior participação das lavouras de grãos, maior uso de tecnologias químicas e mecânicas e maior existência de terras férteis e foi chamado "Agricultura Moderna de Grãos".

\section{Fator 2 - Menos Agricultura Familiar}

Responsável pela explicação de 13,6\% da variância, esse fator está correlacionado com nove variáveis. Apresenta correlação positiva com a área média dos estabelecimentos, com a porcentagem de estabelecimentos com trator, com a participação da mão- 
Tabela 1 - Matriz de correlações entre Fatores e Variáveis (matriz de estrutura dos fatores) com as comunalidades das variáveis e a variância explicada pelos fatores

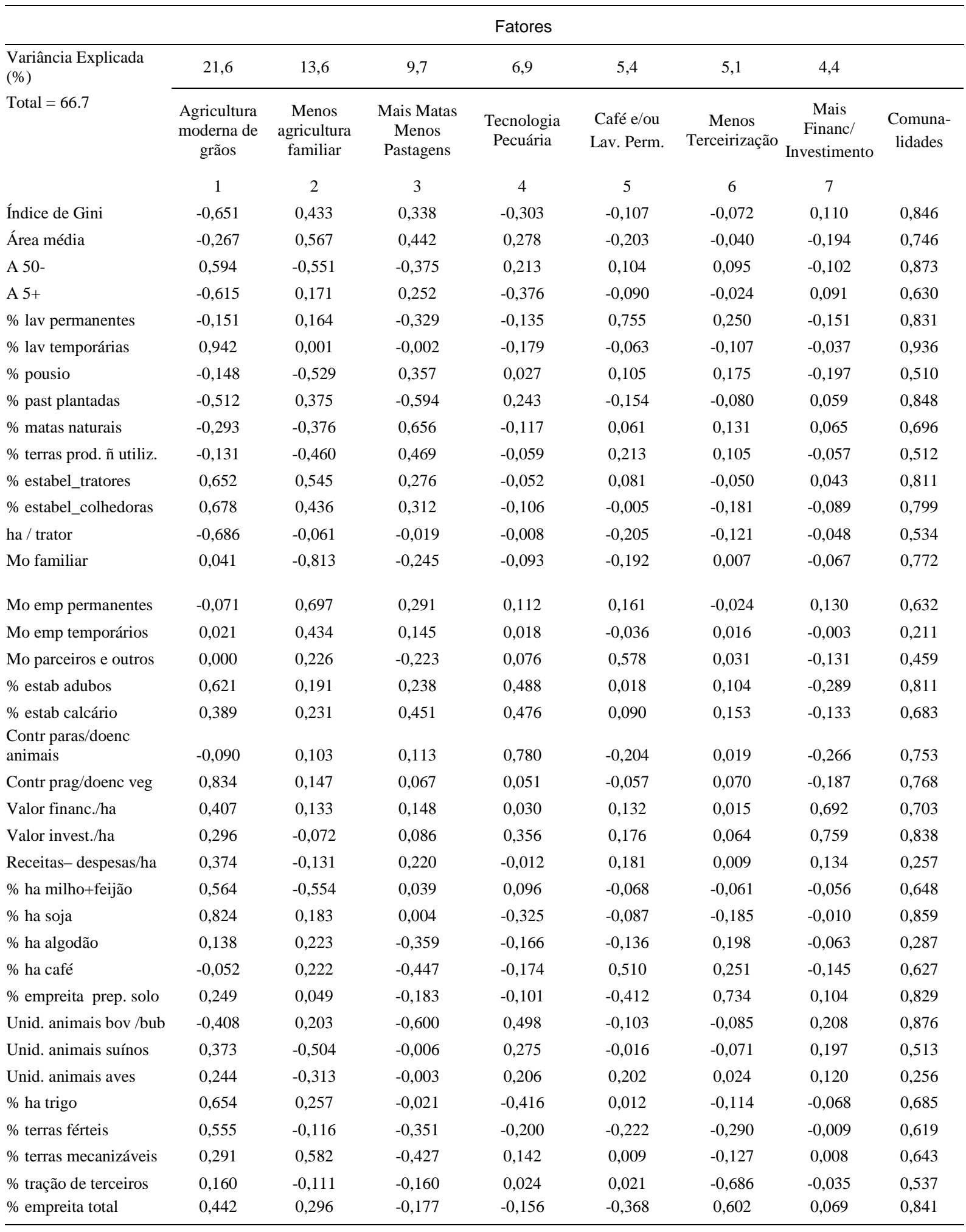

Obs. A comunalidade é uma medida da qualidade de explicação de uma variável e assume valores de 0 a 1 , sendo alta de 0,700 a 1,000 , média de 0,500 a 0,699 e baixa se abaixo de 0,500 .

Ciência Rural, v.36, n.1, jan-fev, 2006. 
de-obra de empregados permanentes e com porcentagem da área de terras mecanizáveis. Apresenta correlação negativa com a porcentagem da área dos $50 \%$ menores estabelecimentos, com a participação da mão-de-obra familiar, com empregados permanentes e com porcentagem da área de terras mecanizáveis. Apresenta correlação negativa com a porcentagem da área de milho mais feijão e de área de lavouras em descanso (pousio) e com unidades animais de suínos por área explorada. Esse fator expressa uma contraposição entre agricultura patronal e agricultura familiar.

\section{Fator 3 - Mais Matas Naturais e Menos Pastagens} Com 9,7\% da variância explicada, esse fator está correlacionado com três variáveis. Apresenta correlação positiva com a porcentagem da área de matas e florestas naturais e correlação negativa com a porcentagem da área de pastagens plantadas e com as unidades animais de bovinos e búfalos por área explorada. Significa uma polarização entre presença de matas nativas e a exploração de pecuária bovina baseada em pastagens plantadas

\section{Fator 4 - Tecnologia Pecuária}

Esse fator está positivamente correlacionado com apenas uma variável que é a porcentagem dos estabelecimentos que utilizam controle químico de parasitas e doenças dos animais, que respondeu por $6,9 \%$ da variância.

\section{Fator 5 - Café e/ ou Lavouras Permanentes}

Positivamente correlacionado com três variáveis que são a porcentagem da área de lavouras permanentes, da área de café e da mão-de-obra de parceiros, esse fator ora detecta a presença de café, ora detecta a presença de outras lavouras permanentes ou os dois, decorrendo disso sua denominação. Explicou 5,4\% da variância total.

\section{Fator 6-Menos Terceirização}

Menos Terceirização está correlacionado com três variáveis. Positivamente com empreita de preparo de solo e empreita total e, negativamente, com utilização de força de tração de terceiros pelo aluguel de máquinas. Esse fator indica uma contraposição entre empreita tradicional e a moderna terceirização via aluguel de máquinas, tendo explicado 5,1\% da variância.

Fator 7 - Mais Financiamentos e Investimentos Este último fator está positivamente correlacionado com duas variáveis: valor dos financiamentos por área explorada e valor dos investimentos por área explorada. Foi denominado
"Mais Financiamento e Investimentos" e explicou 4,4\% da variância.

Comparando estudos anteriores utilizando um elenco similar de variáveis como FUENTES LLANILLO (1984) e FUENTES LLANILLO (1993) tem-se, por um lado, que as informações do Censo Agropecuário 1995/96 são mais limitadas principalmente no que tange a informações sobre despesas que eram utilizadas em algumas variáveis onde se utilizou somente porcentagem de ocorrência, e, por outro, que esse conjunto de variáveis apresentou-se de forma mais complexa em termos de explicação da variância, pois, com os dados do Censo de 1980, três fatores explicaram $67,8 \%$ da variância, com os dados do Censo de 1985, cinco fatores explicaram $70,2 \%$ da variância e, neste trabalho, com os dados do Censo de 1995/96, sete fatores explicaram $66,7 \%$ da variância.

O principal resultado da Análise de Agrupamento é a formação de grupos ou tipos de municípios a partir dos valores dos fatores obtidos na Análise Fatorial. A escolha do número de grupos (clusters ou conglomerados) segue um critério estatístico a partir das distâncias entre os conglomerados que vão se formando pelo método (que indicou um melhor corte em torno de 20 grupos). Entretanto há também um grau relativo de arbitrariedade, pois freqüentemente há grupos minoritários e até individuais que podem confundir a visão do todo. Optou-se por descrever os nove grupos com frequiências iguais ou superiores a oito municípios, juntando outros grupos diferenciados de menor freqüência num décimo denominado "Outros municípios", do qual fazem parte 24 municípios.

$\mathrm{Na}$ figura 1, estão representados os dez grupos ou tipos de municípios. A numeração dos grupos respeita a ordem de ocorrência dos agrupamentos. Os valores médios dos sete fatores para cada grupo são apresentados para apoiar as descrições desses tipos de municípios. O valor de um determinado fator mostra a posição relativa do município em relação às características dominantes do fator. Tais valores comportam-se como variáveis reduzidas, com média zero e variância igual a um. Dessa forma, valores positivos $(>0,5)$ e negativos $(<-0,5)$ significam concordância e antonímia em relação às características do fator. Valores intermediários e próximos de zero significam neutralidade e/ ou uma posição intermediária do município.

A principal constatação visual é que os grupos ou tipos de município não ocorrem de forma aleatória ou dispersa, mas de forma organizada e caracterizando espaços geográficos contínuos, os quais denominamos mesorregiões. Uma mesorregião é 


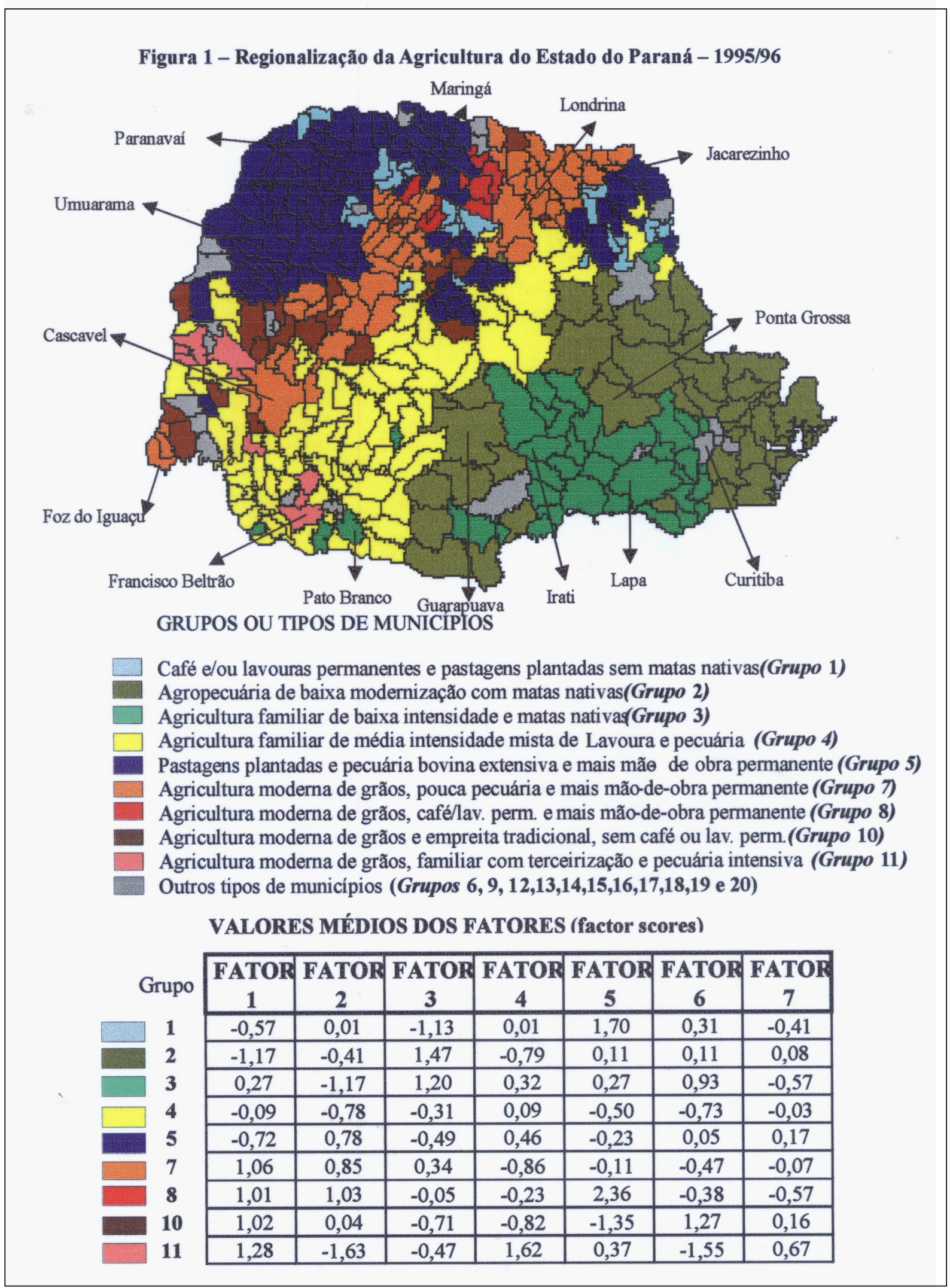

Figura 1 - Regionalização da agricultura do Estado do Paraná - 1995/96

Ciência Rural, v.36, n.1, jan-fev, 2006. 
um espaço geográfico contínuo que reúne um número de municípios maior que o âmbito de uma cidade-polo que caracterizaria uma microrregião. Pode ser formada por um tipo de município assim como pela combinação de mais de um tipo.

Iniciando a descrição dos tipos de municípios a partir do Paraná Tradicional das matas de araucárias e campos nativos, na porção leste e centrosul do Paraná, dois tipos de municípios (grupos 2 e 3) formam três mesorregiões.

Grupo 2 - Agropecuária de baixa modernização com matas nativas

Esse grupo é constituído por trinta e três municípios divididos em duas mesorregiões. Uma delas abrange parte da região metropolitana de Curitiba, Ponta Grossa, Litoral e Ribeira e outra reúne os campos de altitude de Guarapuava e Palmas. Nestes municípios, predomina uma agropecuária extensiva, intermediária entre patronal e familiar, com expressiva presença de matas nativas, onde não são significativos nem empreita, nem aluguel de máquinas. As características modais não revelam as ilhas de agricultura moderna que ali existem (Cinturão Verde de Curitiba, Colônia Witmarsum, Ponta Grossa, Castro, Carambeí e Guarapuava).

Grupo 3-Agricultura familiar de baixa intensidade com matas nativas

Também formado por trinta e três municípios, dentre eles Irati, União da Vitória, Lapa e Palmeira, esse tipo de município está praticamente circunscrito a uma mesorregião onde predomina uma agricultura familiar com pouca modernização, baixo investimento, muitas matas nativas, onde são comuns as empreitas do tipo tradicional. Nessa área, vive um significativo contingente de agricultores familiares descendentes de poloneses, italianos, ucranianos e caboclos que se instalaram na região a partir do fim do século XIX.

Um tipo de município (grupo 4) é o principal constituinte de uma grande mesorregião que se estende de Centro a Sudoeste, com algumas ocorrências no Oeste e Norte.

Grupo 4 - Agricultura familiar de média intensidade mista de lavouras e pecuária com terceirização

Abrange oitenta municípios, dentre eles

Ortigueira, Pitanga, Capanema, Chopinzinho e Santa Helena, onde ocorre uma agricultura familiar de média intensidade, com lavouras e pecuária e significativa terceirização via aluguel de máquinas. Esse tipo de município encerra uma grande gama de situações da agricultura familiar, sendo o segundo grupo mais numeroso.

Quatro tipos de municípios (grupos 7, 8, 10 e 11) conformam um eixo que se estende de Norte a Oeste do Paraná, definindo duas mesorregiões (Norte e Oeste) de agricultura intensiva de grãos onde estão as terras mais férteis do Terceiro Planalto.

Grupo 7 - Agricultura moderna de grãos e pouca pecuária

Nesse tipo de município ocorre uma agricultura moderna de grãos bastante especializada, com grande utilização de mão-de-obra permanente (pouco familiar) e onde há pouca pecuária, poucas matas e é pequena a terceirização de máquinas via aluguel. Fazem parte desse grupo cinqüenta e cinco municípios, dentre eles Cornélio Procópio, Cambará, Londrina, Maringá, Campo Mourão, Cascavel, Foz do Iguaçu.

Grupo 8 - Agricultura moderna de grãos com cafél lavouras permanentes e mão-de-obra permanente

Circunscrito ao Norte do Paraná esse grupo é formado por oito municípios (Arapongas, Rolândia, Cambé, Prado Ferreira, Miraselva, Marialva, Sarandi e Mandaguaçu) com uma agricultura moderna de grãos com alto uso de empregados permanentes (pouco familiar), com bastante café e outras lavouras permanentes.

Grupo 10 - Agricultura moderna de grãos e pouca terceirização

Esse grupo é caracterizado por uma agricultura moderna de grãos, intermediária de familiar e patronal, com poucas matas, pouca pecuária, ausência de lavouras permanentes, predominando empreita do tipo tradicional. São vinte e um municípios, dentre eles Primeiro de Maio, São João do Ivaí, Manoel Ribas, Assis Chateaubriand, Corbélia, Guaíra e São Miguel do Iguaçu.

Grupo 11 - Agricultura moderna de grãos familiar e terceirização

Integrado por oito municípios no Oeste e Sudoeste (Toledo, Marechal Cândido Rondon, Pato Bragado, Entre Rios do Oeste, Capitão Leônidas Marques, Francisco Beltrão, Enéas Marques e Dois Vizinhos) esse tipo apresenta uma agricultura moderna de grãos de caráter familiar, com alta terceirização via aluguel de máquinas, com muita pecuária de elevada lotação e lavouras permanentes ausentes.

Dois tipos de municípios (grupos 1 e 5) são os principais integrantes das três últimas mesorregiões:

Ciência Rural, v.36, n.1, jan-fev, 2006. 
Noroeste, Vale do Ivaí (centro-norte) e Norte Pioneiro. Grupo 5 - Pastagens plantadas, pecuária bovina extensiva e mão-de-obra permanente

Este é o grupo mais numeroso (oitenta e seis municípios) e se caracteriza pela predominância das pastagens plantadas, com expressiva pecuária bovina, sem matas, pouca modernização, muita mão de obra permanente (pouco familiar), sem empreita tradicional nem aluguel de máquinas. Pertencem a esse grupo Paranavaí, Cianorte, Umuarama, Querência do Norte, Colorado, Jaguapitã, Faxinal, Ivaiporã, Jacarezinho, Santo Antonio da Platina e Ibaiti.

Grupo 1 - Café e pastagens plantadas sem matas nativas

Nesse tipo existe uma presença importante de lavouras permanentes, principalmente café, ao lado de muitas pastagens plantadas, expressiva pecuária bovina, sem matas, onde predomina o uso de mão-deobra permanente (pouco familiar). Tal grupo é formado por vinte e três municípios, dentre eles Pinhalão, Ribeirão do Pinhal, Apucarana, Jandaia do Sul, Nova Esperança, Indianópolis e Diamante do Norte.

\section{CONCLUSÕES}

O uso seqüencial da Análise Fatorial e da Análise de Agrupamento continua mostrando eficiência para analisar um numeroso elenco de indicadores mensuráveis relativos a fatores econômicos, sociais, tecnológicos e dos recursos naturais na agricultura.

A Análise Fatorial com trinta e sete variáveis permitiu descrever os sete fatores principais que explicaram $66,7 \%$ da variância. A Análise de Agrupamento dos valores dos sete fatores permitiu classificar dez tipos de municípios, organizados em nove mesorregiões, caracterizando assim a diversidade da agricultura do Paraná.

No chamado Paraná Tradicional das matas de araucárias e campos nativos, dois tipos de municípios (grupos 2 e 3 ) formam três mesorregiões. Uma quarta mesorregião, que se estende de Centro a Sudoeste, é constituída unicamente por municípios do grupo 4. Existe uma faixa formada principalmente por municípios dos grupos 7, 8, 10 e 11, que conforma duas mesorregiões (Norte e Oeste). Finalmente existem três mesorregiões (Noroeste, Vale do Ivaí e Norte Pioneiro) constituídas principalmente pelos tipos de município dos grupos 1 e 5 .

\section{AGRADECIMENTOS}

Os autores agradecem ao Projeto Paraná 12 Meses do Governo do Paraná e BIRD pelo custeio da linha de pesquisa; ao professor Rodolfo Hoffmann, pela valiosa revisão e pelas sugestões, e aos amigos Moacyr Doretto, Tiago Pellini e Antonio Carlos Laurenti do IAPAR, pela atenciosa cooperação.

\section{REFERÊNCIAS}

CAMPANHOLA, C.; GRAZIANO DA SILVA, J. (ed.). O novo rural brasileiro: políticas públicas. Jaguariúna: EMBRAPA, 2000. Cap.4, p.61-91.

CUNHA, M.S.; CHILANTE, C.A.T. Caracterização da agropecuária paranaense na década 90. Revista Paranaense de Desenvolvimento. Curitiba, n.101, p.3-16, 2001.

FUENTES LLANILLO, R. Caracterização da estrutura de produção agropecuária do estado do Paraná. 1984. 177f. Dissertação (Mestrado em Agronomia) - Escola Superior de Agricultura "Luiz de Queiroz", Universidade de São Paulo.

FUENTES LLANILLO, R. et al. Regionalização da agropecuária Paranaense. In: CONGRESSO BRASILERIO DE ECONOMIA E SOCIOLOGIA RURAL, 1993, Ilhéus (BA). Anais...Chicago SOBER, 1993. V1. p.152-160.

HARMAN, H.H. Modern factor analysis. 3.ed. Chicago: University of Chicago, Chicago, 1976. 487p.

HOFFMANN, R. A dinâmica da modernização da agricultura em 157 microrregiões homogêneas do Brasil. Revista de Economia e Sociologia Rural, Brasília, v.30, n.4, p.271290, 1992.

IBGE. Censo Agropecuário de 1975 - Paraná. n 18. Rio de Janeiro, 1979. 1023p.

IBGE. Censo Agropecuário de 1980 - Paraná. n 20. Rio de Janeiro, 1983. 1125 p.

IBGE. Censo Agropecuário de 1985 - Paraná. n 22, Rio de Janeiro, 1991. 876p.

IBGE. Censo Agropecuário de 1995/96 - Paraná. Rio de Janeiro, 1998. 320p.

JOHNSON, R.A.; WICHERN, D.W. Applied multivariate statistical analysis. Englewood Cliffs, New Jersey: Prentice Hall, 1982. 341p

KAGEYAMA, A.; LEONE, E.T. Uma tipologia dos municípios paulistas com base em indicadores sóciodemográficos. Campinas, SP: Instituto de Economia, 1999. 37p. (nº6).

LAURENTI, A.C. Terceirização na produção agrícola. Londrina, PR: Instituto Agronômico do Paraná - IAPAR, 2000. 201p. (Boletim Técnico n. 63).

MINISTÉRIO DA AGRICULTURA - SECRETÁRIA NACIONAL DE PLANEJAMENTO AGRÍCOLA. Aptidão agrícola das terras do Paraná. Brasília, 1981. v.21, $141 \mathrm{p}$.

MORRISON, D. Multivariate statistical methods. New York. Mc Graw-Hill, Series on Probability and Statistics, 1976. $373 \mathrm{p}$.

SCHNEIDER, S.; WAQUIL, P.D. Caracterização socioeconômica dos municípios gaúchos e desigualdades regionais. Revista de Economia e Sociologia Rural, Brasília, v.39, n.3, p.117142,2001 